\title{
When unforeseen events become strategic
}

\author{
Mette Vinther Larsen and Jørgen Gulddahl Rasmussen
}

\begin{abstract}
This article acknowledges that strategising processes revolve around allowing for continual shifts in an uncertain environment to constructively shape the ways in which managers strategise. The research question pursued in this article is: 'How do unforeseen events shape managerial strategising?' The theoretical background for this article is inspired by research done within the strategy-as-practice and strategy-in-practice communities and uses concepts such as strategic intent, wayfinding/wayfaring and temporal work to explore how the managers from the small Danish Software Company cooperated with actors in the mining industry. This cooperation was initially perceived as an unforeseen event but, incrementally and retrospectively, it became strategic. The main theoretical and practice-anchored findings draw attention to the roles that unforeseen events can play in shaping strategising. These findings underline the significance of prioritising micro-founded actions carried out contextually by strategists when learning more about the who, what and how of strategising.
\end{abstract}

Keywords: wayfaring, strategy-as-practice, qualitative methods, communication, sensemaking

Received 12 February 2015. Accepted 19 April 2017

\section{INTRODUCTION}

T $\mathrm{n}$ the study of strategic processes, it is widely acknowledged that uncertainty and environmental shifts shape how strategic changes are realised in practice (Kaplan \& Orlikowski, 2013; Elbanna \& Fadol, 2016; O’Shannassy, 2016). Far from being orderly, predictable and linear, strategic processes are emergent, nonlinear, incrementally changing and shaped by local sensemaking processes (Mintzberg \& Waters, 1985; Pettigrew, 1992; Balogun \& Johnson, 2004; Balogun, 2006; Jarzabkowski, Balogun, \& Seidl, 2007; Chia \& Holt, 2009; Vaara \& Whittington, 2012). Emphasis is increasingly - both within academia and among practitioners - directed towards the concrete practices following the formulation of strategy, vision, mission and action plans; what often is referred to as the 'black box of strategy work' (Mintzberg \& Waters, 1985; Golsorkhi, Rouleau, Seidl, \& Vaara, 2010; Kaplan \& Orlikowski, 2013; Elbanna \& Fadol, 2016; O’Shannassy, 2016).

The budding interest in the term 'strategising' (Johnson, Langley, Melin, \& Whittington, 2007; Golsorkhi et al., 2010; Vaara \& Whittington, 2012) - the concrete actions people carry out that are either directly linked to the implementation of a strategy or retrospectively turn out to be of strategic significance - exemplifies the increasing interest in practice. Instead of primarily focussing on the effects of strategies, a more comprehensive, incremental and practice-anchored understanding of what actually happens during strategic processes is being embraced (Mintzberg \& Waters, 1985;

Department of Business \& Management, Aalborg University, Fibigerstræde 2, 9220 Aalborg Øst, Denmark

Corresponding author: mvl@business.aau.dk 
Pettigrew, 1992; Jarzabkowski, Balogun, \& Seidl, 2007; Golsorkhi et al., 2010). The increasing focus on strategising characterises both academics and practitioners and has led many researchers within the social sciences to suggest academia and practice should come together in order to develop knowledge that helps support the organisational practices being researched (Hosking \& Pluut, 2010; Galvin, 2014; Gergen, 2015; Ripamonti, Galuppo, Gorli, Scaratti, \& Cunliffe, 2015; Shotter, 2016).

The research focus on concrete actions during strategic processes follows the development toward a broader 'practice turn' within organisational studies (Jarzabkowski \& Spee, 2009; Corradi, Gherardi, \& Verzalloni, 2010; Golsorkhi et al., 2010). The practice turn shift emphasises that knowledge about organisational phenomena should take its point of departure empirically in socially generated practices. Based on this shift in reasoning, strategy and strategic practices can therefore be understood as socially constructed, shared, routinised, meaningful and valuable ways of acting and making sense of what happens as a strategy is realised (Whittington, 2006; Jarzabkowski, Balogun, \& Seidl, 2007; Jarzabkowski \& Spee, 2009).

In particular, the strategy-as-practice ( $s$-as-p) community has embraced a practice-based approach to strategy, arguing that strategy is not the property of an organisation or something that the organisation has (Jarzabkowski, Balogun, \& Seidl, 2007; Jarzabkowski \& Spee, 2009; Golsorkhi et al., 2010). Instead, strategy is something that actors do, and the doers are employees, middle managers, top leaders and various stakeholders both within and beyond the organisation (Whittington, 2006; Johnson et al., 2007). Furthermore, strategic processes are characterised as being unpredictable, context-dependent, nonlinear and often leading to unintended outcomes (Balogun \& Johnson, 2004; Balogun, 2006).

Within the s-as-p community, there have been many attempts to understand what actually happens during strategic processes in both empirical and theoretical terms (Jarzabkowski \& Spee, 2009; Golsorkhi et al., 2010; Vaara \& Whittington, 2012). These attempts range from focussing on new institutional theory (Suddaby, Seidl, \& Le, 2013) to exploring local interpretations and dynamic capabilities (Regnér, 2008; Rouleau \& Balogun, 2011). Studies have also examined discursive practices that shape how a strategy is realised (Mantere, 2008; Balogun, Jarzabkowski, \& Vaara, 2011) and how using strategic tools and techniques influence strategising processes (Jarzabkowski, Spee, \& Smets, 2013; Jarzabkowski \& Kaplan, 2014).

Chia and Holt $(2009,2008)$ have - using the term 'strategy-in-practice' (s-in-p) - both challenged and supplemented existing s-as-p theories by arguing how strategic processes are characterised by unpredictable twist and turns. Following a s-in-p perspective, strategising is shaped by unforeseen, unplanned, and unintended events, wherein people cope and do their best to make sense of events as they unfold (Chia \& Holt, 2006, 2009). Hence, it is not possible to presuppose which practices or events will ultimately become strategic. It is only by studying events and practices contextually and exploring how they evolve over time that one can know retrospectively which actions and events will turn out to be of strategic significance (Chia, 2004; Chia \& Holt, 2009). The need for context-rich research on strategic processes that explore who is involved in these processes, how they act, make sense and on which theories, models and mental schemes they rely, has also been advocated by researchers outside the s-as-p and s-in-p communities (see e.g., Pettigrew, 1992; Galvin, 2014; Elbanna \& Fadol, 2016).

Although many studies have been conducted on what actually happens during strategic processes, researchers within the s-as-p and s-in-p communities still encourage scholars to focus on microfounded actions, subtle nuances and how everyday coping activities help to shape strategic practices (Chia \& Rasche, 2010; Vaara \& Whittington, 2012; Kaplan \& Orlikowski, 2013; O’Shannassy, 2015). This article is an attempt to supplement existing knowledge within the s-as-p and s-in-p communities and among practitioners about what happens during strategic processes when they are researched from a micro-founded perspective, with a special emphasis on how unforeseen events shape the strategic processes of an organisation. The research question pursued in this article is: 'how do unforeseen events shape managerial strategising? 
An additionally relevant question is: 'why focus on unforeseen events? Are they not just a part of the everyday practice of organising and strategising?' Yes, they are, and there is nothing surprising or new in arguing that strategies are realised by pursuing paths beyond those that the top management has more formally decided upon and forecasted. Many influential strategy researchers within both the s-as-p and s-in-p communities have illustrated this, as presented above. This article pursues something different, namely an exploration of the significance of unforeseen events in the strategising process. The purpose of this article is twofold: first, to supplement existing knowledge within the s-as-p and s-in-p communities as well as among practitioners about what actually happens during strategic processes; and second, to draw attention to the role that unforeseen events have in shaping an organisation's strategic processes. Pursuing these two purposes is - as mentioned in the introduction above - an acknowledgement of the need to bring practice and academia closer together in order to allow new understandings to emerge from merging these two disciplines. The article will first introduce the theoretical background used in this article. Subsequently, both the research method and the empirical data explored in the article will be presented. Third, three excerpts are presented and discussed based on the theoretical perspective used in the article. Finally, the conclusions and recommendations for further research are conveyed.

\section{THEORETICAL BACKGROUND}

The theoretical background for this article was inspired by research done within both the s-as-p and $s$-in-p communities. Researchers with an s-as-p perspective often strive towards linking microprocesses within a concrete organisation with broader and more general macro-practices in order to reach a more general comprehension of strategy (Jarzabkowski, Balogun, \& Seidl, 2007; Jarzabkowski \& Spee, 2009; Golsorkhi et al., 2010). S-in-p researchers, on the other hand, tend to argue that the ways in which managers and employees strategise in incremental ways and through everyday actions is unique, local and contextual, and linking these microprocesses to more general macro-practices is not possible (Chia \& Holt, 2009). According to Chia and Rasche (2010), Orlikowski (2010) and Feldman and Orlikowski (2011), the differences between an s-as-p and an s-in-p approach can be explained by looking at the epistemological differences between the two perspectives. Both perspectives work with the term 'practice', but they understand and apply the term differently. According to Orlikowski (2010) and Feldman and Orlikowski (2011), practice can be understood and applied in three different ways: (1) as an empirical phenomenon; (2) as a theoretical perspective; and (3) as a philosophy. To understand practice as an empirical phenomenon means to prioritise micro-founded actions that are carried out contextually in practice by managers, employees and so on in their everyday settings without substantial reliance on practice theory (see e.g., Giddens, 1984; Schatzki, 2001; Nicolini, Gherardi, \& Yanow, 2003; Orlikowski, 2010; Vaara \& Whittington, 2012). To understand practice from a theoretical perspective means to explicitly draw on practice theory and epistemologically embrace the fact that practices produce, shape and/or reinforce reality (Orlikowski, 2010; Vaara \& Whittington, 2012). This enables researchers to analyse linkages between micro-activities and macro-institutions (Orlikowski, 2010; Vaara \& Whittington, 2012). Finally, understanding practice as a philosophy necessitates an acceptance of the ontological premises associated with practice theory - practice is constituted by and constitutes a socio-material world (see e.g., Barad, 2003; Orlikowski, 2010; Vaara \& Whittington, 2012; Ingold, 2015). According to Orlikowski (2010) and Vaara and Whittington (2012), s-as-p researchers tend to position their work within an epistemological and/or ontological understanding of practice. On the other hand, Chia and Holt (2006, 2009) and Chia and Rasche (2010) base their work on a Heideggerian ontology and perceive practice as an empirical phenomenon.

In this article, we are inspired by an s-in-p perspective and build upon an understanding of practice as an empirical phenomenon. This means that mundane details, complex microprocesses, and the 
everyday realities - as they are experienced and practiced by managers in organisations - are prioritised as an understanding of how strategising emerges (Orlikowski, 2010). Instead of assigning ontological primacy to practice, in this article ontological primacy is assigned to language. To focus on language and sensemaking among people is part of a broader linguistic turn within organisation studies (Weick, 1995; Alvesson \& Kärreman, 2000; Cunliffe, 2002a). According to Cunliffe (2002a), three premises can be ascribed to the ontological understanding of language: (1) language is metaphorical; (2) language and meaning are embodied practices; and (3) language is indeterminate. The metaphorical aspect of language implies that the way people communicate and co-construct meaning is realitygenerating (Mead, 1932, 1974; Cunliffe, 2002a). The ontological aspect of this is that as people communicate in order to make sense of a particular situation, they co-construct meaning, and this co-constructed meaning is subsequently enacted by the same people. In turn, this process shapes how organisational events unfold (Schütz, 1972; Vološinov, 1973; Weick, 1988; Alvesson, 2002; Cunliffe, 2002a; Alvesson \& Sveningsson, 2008). To argue that language and meaning are embodied practices means drawing attention to the ways in which previous experiences, organisational cultures, and existing meaning-making structures shape what people anticipate and how they communicate, act and co-construct meaning in the present (Vološinov, 1973; Mead, 1974; Weick, 1988; Cunliffe, 2002a). The third premise, that of language being indeterminate, is dialectically related to the second premise. Despite the embedded nature of language, where people come to anticipate certain events, most situations are characterised by the above-mentioned emergence of unpredictable, uncertain and unforeseen events (Cunliffe, 2002a; Kaplan \& Orlikowski, 2013; Elbanna \& Fadol, 2016; O'Shannassy, 2016). Managers and employees often cooperate with people outside their organisation, who embed other experiences, live in a different organisational culture, and whose existing structures of meaning differ. These differences shape the cooperation between people both within and beyond organisations, and as their different and embedded behaviours and methods of communication converge, events, ideas, proposals, and possibilities emerge, which were unforeseen. Language is also indeterminate, and therefore unforeseen events, ideas, proposals and possibilities can, in one way or another, shape how people co-construct meaning and act as they begin to cooperate. By perceiving practice as an empirical phenomenon and studying how micro-founded actions develop over time, it becomes possible to see that as a new cooperation is initiated, people inside an organisation incrementally begin to talk and act differently. Furthermore, how these subtle changes make room for the strategisation of unforeseen events to become strategic.

\section{Strategising in an uncertain environment}

As the ontological primacy of language - as applied in this article - indicates, people's actions and the meaning that they co-construct constitute how organisational life unfolds. This means that when an understanding of strategising based on an empirical understanding of practice emerges, the focus becomes how mundane details, complex microprocesses and everyday realities are experienced and practiced by people in organisations. Jarzabkowski, Kaplan, Seidl, and Whittington. (2016) argue that studying strategy from a practice perspective implies that researchers pay attention to: (1) what happens during strategic processes; (2) who participates; and (3) how they go about strategising as integrated processes. As Jarzabkowski et al. (2016) state, 'outcomes depend on the interaction of all three aspects' (p. 249). Researchers within the s-as-p community have previously used other terms with the same emphasis and meaning: practitioners (who); practices (what); and praxis (how) (Whittington, 2006, 2007; Jarzabkowski, Balogun, \& Seidl, 2007; Johnson et al., 2007; Golsorkhi et al., 2010).

Some scholars (Mintzberg \& Waters, 1985; Jarzabkowski, Balogun, \& Seidl, 2007; Chia \& Holt, 2008; O'Shannassy, 2016) present the need to research strategising as it happens in situ because of the previously mentioned complexity and unpredictability that characterises most strategy work today. This has led 
scholars both within and beyond the s-as-p and s-in-p communities to argue for a need to rethink strategy and make room for more integrative and dynamic understandings of what actually happens during strategic processes (Jarzabkowski et al., 2016; O’Shannassy, 2016). Jarzabkowski et al. (2016) suggest that the distinction between deliberate and emergent understandings of strategy is reconciled, because in practice improvisation and local interpretations and adjustments of formulated strategies are integrated and characterise strategising. No strategy completely follows the initially established route (Mintzberg \& Waters, 1985; Willert \& Larsen, 2015; Jarzabkowski et al., 2016; O’Shannassy, 2016). O’Shannassy (2016) suggests talking about strategic intent rather than strategic planning when it revolves around strategising in ways that bring a desirable future closer to the present. To focus on strategic intent is an acknowledgement of the bounded rationality that all managers face (Simon, 1991). Environments are uncertain and actions unfold in ways that, from the manager's embedded perspective, are unforeseen as a strategy is set in motion (O'Shannassy, 2016). This means that paying attention to and working creatively and constructively with the way people within and beyond the organisation act and co-construct meaning during strategic processes is of significance if a strategy is indeed to be realised (Willert \& Larsen, 2015; Jarzabkowski et al., 2016; O’Shannassy, 2016).

Ingold $(2008,2010,2011)$ has presented the term 'wayfaring', which Chia and Holt $(2006,2008$, 2009) introduced to the strategy literature with their term 'wayfinding'. Wayfaring/wayfinding refers to embracing and working constructively with the unpredictable and unforeseen events that emerge as you move from one place to the next (Chia \& Holt, 2009; Ingold, 2011). As managers strategise, they envision a desirable future that they - based on their actions and communication - attempt to bringer closer to the present. In the process of wayfinding/wayfaring, managers know that the strategy will only be realised if they constantly change and incrementally rework the previously formulated strategy to make it adapt to the surrounding environment (Vaara \& Whittington, 2012; Kornberger, 2013). To wayfare/wayfind implies acknowledging that how managers handle unforeseen events that emerge as a strategy is set in motion shapes how a strategy is realised (Chia \& Holt, 2009; Willert \& Larsen, 2015).

To acknowledge and constructively embrace events which, seen from a manager's perspective, were initially unforeseen involves what Kaplan and Orlikowski (2013) call 'temporal work'. Temporal work revolves around; 're-seeing the past' (Kaplan \& Orlikowski, 2013: 967), imagining a new future and allowing these new 're-seeings' and 'imaginings' to shape the way people communicate and act in the present as they strategise (Kaplan \& Orlikowski, 2013). From the ontological understanding of language, as applied in this article, this revolves around working actively with the presented third premise: that is, language is unpredictable. It revolves around being able to talk and enact a different reality into being. When managers strategise based on their embedded language, they attempt to bring a desirable future into the present that is congruent with their previous experiences, organisational culture and existing structures of meaning. To engage in temporal work means to move beyond the embedded and to 'wayfare' in ways where unforeseen events are explored and experimented with - even if it means deviating from the original strategic plan. It is a process of working creatively and constructively with the possibilities that the unforeseen events offer, and exploring whether pursuing them will make the realisation of the strategic intentions possible (Willert \& Larsen, 2015; Jarzabkowski et al., 2016; O’Shannassy, 2016). This kind of strategising will, as Chia and Holt (2009), Mintzberg and Waters (1985) and Vaara and Whittington (2012) write, mean that not all strategising can be planned upfront. Part of what we term as strategic is in fact a 'second-order label' (Vaara \& Whittington, 2012) that is retrospectively attributed to certain actions and practices that turn out to be strategic - as in, for example, unforeseen events.

\section{RESEARCH METHOD}

The research method applied in generating the data that we use in this article is a longitudinal qualitative 'action-learning project' (Revans, 1983, 1992). The project lasted $\sim 2$ years, and five small 
Danish companies in the wind power industry participated. The action-learning project consisted of two connected activities: (1) Seven quarterly 3-5-hr-long joint action-learning seminars where the six researchers and the nine managers who were involved in the project participated; and (2) 21 quarterly inquiring conversations that lasted $1.5-2 \mathrm{hr}$. These inquiring conversations were held at the respective companies and only one or two of the researchers and the managers of the specific company participated. The data for this article stems from inquiring conversations held in one of the five companies: the Software Company ${ }^{1}$ (SC). During the 2 years, nine inquiring conversations were held between the researchers and SC's three managers, Ella, Christian and Sebastian. During the inquiry conversations, detailed field notes were created by both researchers. In addition, internal documents, SC's website, newspaper articles, and other information about SC were also studied and are included in the data material used in this article.

Action-learning is a research method that focusses on managers jointly discussing and potentially solving small concrete and current problems by raising questions and exploring them individually from various perspectives (Revans, 1977, 1981; Pedler, Burgoyne, \& Brook, 2006). The purpose of this method is that the participating managers invite each other to reflect upon their existing and embedded understandings of a problem, and explore whether there are other and - from the individual manager's perspective - more constructive ways to deal with it (Revans, 1977, 1981; Pedler, Burgoyne, \& Brook, 2006). Thus, action-learning is a method that is congruent with the strategic perspective applied in this article because focus is directed towards how mundane details, complex microprocesses, constructed meaning and the actions carried out constitute the who, what and how of strategising.

To use the term 'inquiring conversations' draws attention to two of the co-constructive aspects of the data generated (McNamee \& Hosking, 2012). Cunliffe (2001, 2011) and Shotter and Cunliffe (2003) use the term 'co-authoring' as a way to describe how the generation of data during the inquiring conversations with managers can be understood as a co-constructive practice. Ella, Christian and Sebastian chose the topics for discussion, but during the inquiring conversations, we, as researchers, offered different perspectives and explored how concrete challenges could be understood and handled (Cunliffe, 2001; McNamee \& Hosking, 2012; Ruwhiu \& Cone, 2013; Galvin, 2014). This indicates the importance of our role as researchers to be self-reflexive about the co-constituting role we play as the who, what and how of strategising is explored - especially when the purpose is to generate data on how mundane details, complex microprocesses and the everyday realities are experienced and practiced by people inside the organisations. Galvin (2014) suggests researchers use an 'inside-out' approach when they inquire into supporting the co-construction of context-sensitive data. To apply an inside-out approach when generating data means to focus on events and situations that are considered particularly relevant by the participating managers (Galvin, 2014). As these events and situations are explored, researchers can apply a 'not-knowing' (Anderson \& Goolishian, 1992) perspective as they inquire. Anderson and Goolishian (1992) argue that if researchers want to learn how people in organisations co-construct meaning and handle challenges, they must remain curious and explorative and not assume that they know what the specific event explored revolves around, nor what is at stake for the managers involved. We, as researchers, have no knowledge about how Ella, Christian and Sebastian's previous experiences, organisational cultures and existing structures of meaning shape what they anticipate and how they communicate, act and co-construct meaning. To ensure that the data generated during the inquiry conversations was context-sensitive and co-authored in ways that resonated with the previous experiences, organisational cultures and existing meaning structures of the three managers, we wrote a four to five-page summary after each inquiry conversation.

1 Both the name of the company and the managers are pseudonyms to respect agreed anonymity with the participating managers. The industries mentioned in the article represent the original industries. 
These summaries were sent to Ella, Christian and Sebastian with an invitation for them to further co-author and rewrite the summaries in ways that they found meaningful.

The need to be self-reflexive and to apply an inside-out approach and a not-knowing perspective in the co-authoring of data not only applied in the process of generating data; it also applied to our subsequent work with the data generated during the inquiry conversations. In total, we have field notes from more than $25 \mathrm{hr}$ of inquiry conversations with Ella, Christian and Sebastian, as well as nine co-authored summaries, and in the process of generating data for this article some activities have been prioritised at the cost of others (Robson, 2011; McNamee \& Hosking, 2012). The data chosen for this article centres solely around SC's cooperation with the mining industry. This kind of prioritisation and reconstruction of data is an integral part of writing up research (Cunliffe, 2002b; Johnson et al., 2007; Robson, 2011; McNamee \& Hosking, 2012). To remain attentive to the previous experiences, organisational cultures and existing meaning structures of Ella, Christian and Sebastian, along with upholding the inside-out approach, we have applied three principles: (1) We have contextualised the data produced for this article to the total amount of data generated during the 2-year-long actionlearning project. The purpose was to ensure that the jargon and meaning structures used in the excerpts resonate with what Ella, Christian and Sebastian expressed throughout the 2 years. (2) We sent early versions of the three excerpts in this article to the three managers of SC with an invitation for them to rewrite them in ways they found meaningful in order to strengthen the context-sensitivity and to make the excerpts and discussions resonate with Ella, Christian and Sebastian's previous experiences, organisational cultures and existing meaning structures. Based on their co-authoring, the excerpts and discussions were reworked in order to ensure that they represented events that the three managers had considered particularly relevant for them over the 2-year period. (3) We have discussed the excerpts and analyses in this article with the other researchers who participated in the action-learning project in order to ensure that the text-context combinations we made were plausible and resonated with their interpretations of SC. Furthermore, we wanted to ensure that the methods used in the discussions offer trustworthy and credible understandings of the researched processes (Kvale, 1992; McNamee \& Hosking, 2012).

\section{Introduction of the software company}

SC was founded in 2001 by the three owners Ella, Christian and Sebastian, who also manage the company. SC is the outcome of a joint collaboration between a Danish university and a larger IT company. SC has 20 employees and specialises in knowledge management systems for the optimisation of technical troubleshooting processes. The three managers all have technical masters' degrees and their software is primarily applied in the telecom industry. Recently, the company sells its products and solutions globally, but as the research began, SC had just begun cooperating with the wind power industry. SC is managed in an informal manner, and the three managers rarely allocate time for the long-term planning of the strategic course of the company. They do not have a formulated strategy, nor do they conduct SWOTs or any other strategic analyses. Ella, Christian and Sebastian tacitly share a vision about the future that intuitively influences their discussions about which markets and customers they should pursue. The tacit and intuitive aspects do not mean that Ella, Christian and Sebastian are not strategic in their practice. It does, however, mean that if we, as researchers, want to learn more about the who, what and how of their strategising, then we have to apply an inside-out and not-knowing approach. We have to embrace a comprehensive approach, be curious and pay attention to how Ella, Christian and Sebastian informally, and based on these mundane and everyday practices, discuss and incrementally enact a given way of strategising into being.

Based on the inquiry conversations with the three managers, an understanding of the tacit and intuitive vision that shaped their managing and strategising emerged. In the production of 
troubleshooting software, SC focusses primarily on the technical aspects and less on the user interface. Pursuing this vision is not without challenges. SC cooperates primarily with the telecom industry and customers in this sector often find it difficult to use their software. The technical staff in the telecom companies that SC cooperates with have no problems identifying all of the technical possibilities and benefits of their products. However, the employees in the customer service departments of telecom companies - who have to use the system and do not possess the same technical skills - struggle with the software. They express that the system is too complex and not user friendly enough. These reactions frustrate the three managers because they feel forced to move away from what they perceive as their core competences in order to meet customer demand. They prefer to stay with their core competences and this is the reason why SC has begun to explore whether their 'technical focus' might be more attractive in the wind power industry.

\section{FINDINGS AND DISCUSSIONS}

In the following subsections, SC's cooperation with the mining industry will be presented and discussed, based on three excerpts. As mentioned above, SC had primarily focussed on the telecom industry and had just begun cooperating with the wind power industry. This change in focus may seem a bit strange. The fact that companies producing heavy machinery for the mining industry would be interested in the technical troubleshooting software SC developed was something Ella, Christian and Sebastian had never anticipated. Furthermore, none of the three leaders had expected that SC's cooperation with the mining industry would become incrementally strategic; therefore, this cooperation is a good illustration of the ways in which unforeseen events can become strategic.

The exploration consists of three excerpts: (1) May, Year 1, when the three managers mentioned the mining industry for the first time; (2) August, Year 1; and (3) November, Year 1. In the excerpts below, we present how Ella, Christian and Sebastian talked about and reflected upon their activities in the mining industry. After each excerpt, a theoretically anchored discussion follows, wherein the authors reflect on how the unforeseen event incrementally shapes the way Ella, Christian and Sebastian strategise.

\section{First excerpt: May, Year 1}

At the end of the meeting in May, Year 1, Christian told the researchers that SC had just finished a successful pilot project with an important company in the mining industry (MAX). They had not cooperated with the mining industry before, and the three managers perceived the cooperation with MAX as a peripheral and isolated project. It differed somewhat from their activities in their primary and secondary markets: namely, the telecom industry and the wind power industry. Ella, Christian and Sebastian originally held talks with MAX as an experiment. The fact that it led to a contract surprised them. While the pilot project with MAX was running, Christian received a phone call from Charles, an independent consultant who specialises in software solutions within the mining industry. Charles had read an article that casually mentioned SC's troubleshooting software systems, and he believed that SC's troubleshooting software was just what several big customers within the mining industry were looking for.

Ella, Christian and Sebastian were a bit astonished about these two unforeseen events, but they were also curious about whether or not the mining industry could be of interest to them. They agreed to investigate the industry further and decided to meet with Charles and visit at least one mining conference in the near future. Their initial sense, based on their cooperation with MAX, was that there could be a potential fit between their troubleshooting software and the mining industry's needs. On the other hand, they had their reservations. They knew from previous experience that once 
preliminary contact was established, the possible customer quickly realised that either the complexity of SC's troubleshooting software exceeded their needs, or they could and would not make the financial and time-related investments that the system required to function efficiently.

\section{The unforeseen event occurs}

What the first excerpt illustrates is how the who, what and how of strategising is shaped by the first two premises of an ontological understanding of language. Ella, Christian and Sebastian discussed and enacted a strategic focus into being even though the telecom industry was perceived as the primary industry with which to cooperate. Even though on several occasions they had experienced that their vision for SC was difficult to reconcile with the needs and desires of the telecom industry, the strategic future that they imagine and try to bring into the present was still primarily constituted by cooperating with the telecom industry. Based on their previous experiences with the telecom industry, they have constructed an organisational culture in which they accept that technological misfits between their core competences and the needs of the customer are a part of their livelihood. In turn, this understanding is embedded, shaping the meaning structures that Ella, Christian and Sebastian draw on as they act and communicate. As their embedded ways of acting and communicating converge with those of Charles and representatives from MAX, new opportunities emerge. The possibility to cooperate with producers of heavy machinery in the mining industry was - perceived from the perspective of the three managers - an unforeseen event that differed from their existing ways of strategising.

As Ella, Christian and Sebastian had no previous experience with cooperating with the mining industry, they relied on their previous experiences in cooperating with the telecom industry as they talk and act. Due to the ontological perspective on language applied in this article, experience has led Ella, Christian and Sebastian to embed certain structures of meaning, and this makes them anticipate that the mining industry, like the telecom industry, will not be able to handle the complexity of SC's troubleshooting software or they are not able to make the financial and time-related investments required by the system to function efficiently. However, the third premise of the ontological understanding of language plays a small trick on the three managers. The unforeseen event - the phone call from Charles - and Ella, Christian and Sebastian's early intuition, which told them that there could potentially be a fit between their troubleshooting software and the mining industry's needs, shaped the way they communicated and acted. They were curious and instead of following a strategic plan, they were guided by strategic intent and the vision they tacitly had for SC, meaning that they worked constructively and creatively with the unpredictable way people from the mining industry reacted.

\section{Second excerpt: August, Year 1}

Not long after the meeting began in August, Year 1, Ella and Christian told the researchers that they planned to attend yet another conference in Norway on mining industry maintenance. They wanted to investigate what the other troubleshooting software suppliers were offering the mining industry. Their preliminary investigations of the mining industry over the last months had indicated that there was potentially a great need for SC's troubleshooting software. In addition, MAX had expressed great satisfaction with their systems, and what really excited Ella, Christian and Sebastian was how easily applicable their systems were to the mining industry. SC was used to dealing with customers' detailed requests regarding user interface and user-friendliness. These requests were, as mentioned above, perceived to lie beyond SC's core competences. Much to their surprise, this was not the case with the mining industry. It seemed as though SC's focus on the technical aspects of the troubleshooting software resonated with the widespread engineering approach to technology in the mining industry. Many of the customers in the mining industry had well-qualified technicians who were not concerned 
about user interface, but rather were more interested in the technological aspects of the systems. Furthermore, it seemed as though the companies in the mining industry were prepared to invest sufficient time and money to get the troubleshooting software to work efficiently. SC was still cooperating with Charles and by attending mining conferences together with him they could see how well-connected he was within the industry. Charles also had many important insights to share with them about the mining industry. Charles had also helped SC develop material about their troubleshooting software with technical terms that were aimed directly at the mining industry.

\section{Exploring the unforeseen event}

From the second excerpt, it becomes apparent that there has been a shift regarding the who, what and where of strategising. Ella, Christian and Sebastian have begun talking and acting in ways unlike their existing and embedded patterns. Indeed, they have begun engaging in a process of wayfaring/ wayfinding. Instead of hanging on to existing experiences from the telecom industry, they work constructively and explore the unpredictable and unforeseen aspects of cooperating with the mining industry even though they do not know where the explorations will take them.

Their cooperation with Charles supports their wayfaring/wayfinding. He functions as a sort of cultural translator between the meaning structures that Ella, Christian and Sebastian embed and how MAX representatives and other central producers of heavy machinery in the mining industry embed. The three managers initiate a temporal work process wherein they incrementally begin to 're-see' their past and imagine a new future. Instead of attempting to bring about a desirable future - whereby primarily cooperating with the telecom industry would be the right way to strategise - Ella, Christian and Sebastian begin constructively working with the possibilities that the unforeseen cooperation with the mining industry has to offer. They begin to explore whether this new way of strategising better fits with the strategic intent that they envision for SC.

Incrementally, this wayfaring/wayfinding and temporal work brings about new experiences that are anchored within the mining industry and not the telecom industry. This sparks a change in the organisational culture; they begin to question if the telecom industry, where they have to accept technological misfits between SC's core competences and the needs of customers, has to be a part of their livelihood. This means that the structures of meaning that they have drawn on as they act and communicate have expanded and suddenly they have begun to envision, discuss and act another strategy into being.

\section{Third excerpt: November, Year 1}

The meeting had just begun in November, Year 1, as Christian began to talk about the progress within the mining industry. Their working relationship with MAX had expanded. MAX had successfully installed SC's troubleshooting software in most of their mining equipment, and as a spin-off benefit, MAX was interested in installing SC's troubleshooting management systems into the heavy machines that they were producing for other industries as well. Ella, Christian and Sebastian expressed how expanding the working relationship with MAX was a move towards further cementing SC's strategic focus on the mining industry. In addition, the three managers explained how they had just agreed to run a pilot project to test SC's troubleshooting software with MEDIUM, another key producer of heavy machinery within the mining industry. Sebastian was confident that it would turn out well, as it had with MAX. Typically, a pilot project led to an agreement for the initiation of an actual working relationship, and it seemed as though the technicians at MEDIUM were just as technically mature as at MAX.

Their cooperation with Charles had ended, as Charles had been hired by a large company in the mining industry to run a 3-year project regarding troubleshooting solutions. Even though Ella, 
Christian and Sebastian could no longer rely on Charles' expertise and support, they felt that the contacts and working relationships that SC had established so far with key customers in the mining industry were strong enough for them to continue increasing their strategic focus on the mining industry. The possibility of further developing the technical aspects of the troubleshooting software, which Ella, Christian and Sebastian perceived as their core competency, by cooperating with the mining industry was originally unforeseen, but it turned out to be strategically significant.

\section{The unforeseen event becomes strategic}

The third excerpt illustrates how Ella, Christian and Sebastian continued their wayfaring/wayfinding and temporal work since the researchers' visit in August. They had further explored and constructively and creatively worked with the unforeseen event of meeting Charles by cooperating with the mining industry. With curiosity and experimentation, they investigated whether the possibilities for pursuing their vision and further strengthening their core competences could be easily accomplished by primarily cooperating with the mining industry instead of the telecom industry. Ella, Christian and Sebastian gradually generated experiences by cooperating with MAX. This more contextually anchored experience shaped the meaning structures embedded and drawn upon by Ella, Christian and Sebastian as they initiated their cooperation with MEDIUM. They began to incrementally discuss and act another reality into being. Through this process, their organisational culture also began to change in such a way that they no longer had to accept the technological misfits between SC's core competences and the needs of customers.

Cooperating with the mining industry might have been a diversion from their original, tacitly shared and informal strategic plans back in May, Year 1, but as Ella, Christian and Sebastian began to wayfare/ wayfind, explore and experiment in cooperating with the mining industry, they realised that the possibilities this cooperation offered were more congruent with SC's strategic intent and their vision. These processes support the argument of Jarzabkowski et al. (2016) regarding the ways in which strategic processes - in practice - are shaped by improvisation, local interpretation and the adjustments of formulated strategies. As argued by Kornberger (2013) and Vaara \& Whittington (2012), strategising revolves around constantly changing and incrementally reworking a strategy in order to enable a company to realise strategic intentions in ways that are aligned with an uncertain environment.

The re-seeing of their past and the imagining of a new future that Ella, Christian and Sebastian embarked on in August, Year 1, incrementally led to a situation where in September, Year 1, they had embedded other ways of discussing and acting. Perceived from an ontological perspective on language, language and actions incrementally shift and allow for new visions and desirable futures to shape the strategising process of Ella, Christian and Sebastian. In September, Year 1, Ella, Christian and Sebastian talked and acted in ways that suggest that the strategic significance for cooperating with the mining industry is embedded and in turn begins to shape the structures of meaning that they use. This change in ways of communicating and acting supports the argumentation by Vaara and Whittington (2012) and Chia and Holt (2009) that not all that is labelled as strategic can be stated upfront. Sometimes strategy is a second-order label that is attributed to some actions and events - as in this case with unforeseen events - incrementally and retrospectively.

\section{CONCLUSIONS}

The purpose of this article has been twofold: (1) to supplement existing knowledge within the s-as-p and s-in-p communities and among practitioners about what actually happens during strategic processes; and (2) to draw attention to the role that unforeseen events have in shaping an organisation's strategic processes. These purposes were pursued through the article's research question: 'how do unforeseen events shape managers' strategising?' With this article, we aimed to enrich and contribute to 
existing knowledge among both practitioners and researchers. If we as researchers want to learn more about the who, what and how of strategising, then prioritising micro-founded actions carried out contextually in practice by managers or other strategists in their everyday setting is of utmost importance. If increasing uncertainty is to be dealt within strategic and constructive ways, managers and other strategists should be invited to take part in talking and acting new understandings of strategising into being. The ontological perspective on language applied in this article supports this move as it emphasises how people are able to make room for new understandings and practices to emerge when they converge their embedded structures of meaning and allow the indeterminate aspects of language to shape how unforeseen events are ultimately understood.

Based on the theoretical perspective, empirical data presented in this article, and the discussions that took place, we conclude that the ability to acknowledge and constructively incorporate an environment's uncertain shifts into the ways that managers strategise is becoming increasingly important. To embrace this, managers - like Ella, Christian and Sebastian - must pay constant attention to the ways in which existing and potential customers and business partners act and communicate, identify new needs for a business or market, make new connections between services and products, and in constructive and explorative ways allow unforeseen events to sometimes influence and shape the who, what and how of their strategising. In order to do this effectively, managers must embark on wayfaring/ wayfinding processes and engage in temporal work by exploring and experimenting with unknown markets and businesses by moving beyond their previous experiences, challenging their organisational culture and reworking their structures of meaning. Often, as with Ella, Christian and Sebastian, these processes take time and often it is not immediately clear where these wayfaring/wayfinding processes will take them. The only thing guiding them is their strategic intent and the future that they envision.

The findings draw attention to the complex and unpredictable processes of strategising, and it underlines how significant it is that researchers, interested in generating knowledge about strategising, prioritise microfounded actions carried out contextually by managers in their everyday settings. Inquiring into these actions and understanding how managers re-see the past and imagine new futures can 'help [researchers] to better comprehend how and why some practices - and not others - come to be seen as "strategic" (Vaara \& Whittington, 2012: $314 \mathrm{f}$ ). The findings and conclusions we present here supplement existing knowledge within the s-as-p and s-in-p communities and among practitioners about what actually happens during strategic processes, by illustrating how the effective handling of unforeseen events is found in some of the subtle nuances and coping activities that help shape how managers and other strategists strategise.

The findings we present in this article identify at least three areas that could be further researched: (1) how researchers can understand in greater detail how unforeseen events shape the what, how and who of strategising; (2) how researchers can invite practitioners to co-author understandings of how strategists incrementally adjust their practices to align with an uncertain environment; and (3) how existing knowledge within the s-as-p and s-in-p communities can be supplemented by researching strategising from a perspective that underlines the ontological aspect of language. These avenues for future research are merely three out of many possibilities, and we hope that this article piques the interest of other researchers in further exploring how unforeseen events become strategic or other aspects of the 'black box of strategy' work.

\section{ACKNOWLEDGEMENT}

The authors wish to thank Associate Professor Allan Næs Gjerding, the chief-editor of Journal of Management \& Organization and the two anonymous reviewers for their supportive and very constructive comments on earlier drafts of this article.

\section{References}

Alvesson, M. (2002). Understanding organizational culture. London: Sage. 
Alvesson, M., \& Kärreman, D. (2000). Taking the linguistic turn in organizational research - Challenges, responses, consequences. Journal of Applied Behavioral Science, 36, 139-158.

Alvesson, M., \& Sveningsson, S. (2008). Changing organizational culture, cultural change work in progress. London: Routledge.

Anderson, H., \& Goolishian, H. (1992). The client is the expert: A not knowing approach to therapy. In S. McNamee, \& K. J. Gergen (Eds.), Therapy as social construction (pp. 25-39). Newbury Park, CA: Sage.

Balogun, J. (2006). Managing change: Steering a course between intended strategies and unanticipated output. Long Range Planning, 30(2), 81-91.

Balogun, J., Jarzabkowski, P., \& Vaara, E. (2011). Selling, resistance and reconciliation: A critical discursive approach to subsidiary role evolution in MNEs. Journal of International Business Studies, 42(6), 765-786.

Balogun, J., \& Johnson, G. (2004). Organizational restructuring and middle manager sensemaking. Academy of Management Journal, 47(4), 523-549.

Barad, K. (2003). Posthumanist performativity: Toward an understanding of how matter comes to matter. Signs, 28(3), 801-831.

Chia, R. (2004). Strategy-as-practice: reflections on the research agenda. European Management Review, 1, 29-34.

Chia, R., \& Holt, R. (2006). Strategy as practical coping: A Heideggerian perspective. Organization Studies, 27(5), 635-655.

Chia, R., \& Holt, R. (2008). Strategy as wayfinding, Paper for the 24th EGOS Colloquium, Amsterdam.

Chia, R., \& Holt, R. (2009). Strategy without design. The silent efficacy of indirect action. Cambridge: Cambridge University Press.

Chia, R., \& Rasche, A. (2010). Epistemological alternatives for researching strategy as practice: Building and dwelling world-wide. In D. Golsorkhi, L. Rouleau, D. Seidl \& E. Vaara (Eds.), Cambridge handbook of strategy as practice (pp. 34-46). Cambridge: Cambridge University Press.

Corradi, G., Gherardi, G., \& Verzalloni, L. (2010). Through the practice lens: Where is the bandwagon of practicebased studies heading? Management Learning, 41(3), 265-283.

Cunliffe, A. L. (2001). Managers as practical authors: Reconstructing our understanding of management practice. Journal of Management Studies, 38(3), 351-371.

Cunliffe, A. L. (2002a). Social poetics as management inquiry - A dialogical approach. Journal of Management Inquiry, $11(2), 128-146$.

Cunliffe, A. L. (2002b). Reflexive dialogical practice in management learning. Management Learning, 33(1), 35-61.

Cunliffe, A. L. (2011). Qualitative research Morgan and Smircich 30 years on. Academy of Management Processings, $14(4), 647-673$.

Elbanna, S., \& Fadol, Y. (2016). The role of context in intuitive decision-making. Journal of Management \& Organizations, 22(5), 642-661.

Feldman, M. S., \& Orlikowski, W. J. (2011). Theorizing practice and practicing theory. Organization Science, 22(5), $1240-1253$.

Galvin, P. (2014). A new vision for the Journal of Management \& Organization: The role of context. Journal of Management, 20(1), 1-5.

Gergen, K. J. (2015). From mirroring to world-making: Research as future forming. Journal for the Theory of Social Behaviour, 45(3), 287-310.

Giddens, A. (1984). The constitution of society. Cambridge: Polity Press.

Golsorkhi, D., Rouleau, L., Seidl, D., \& Vaara, E. (2010). Cambridge handbook of strategy in practice. Cambridge: Cambridge University Press.

Hosking, D. M., \& Pluut, B. (2010). (Re)constructing reflexivity: A relational constructionist approach. The Qualitative Report, 15(1), 59-75.

Ingold, T. (2008). Lines. A brief story. Oxon: Routledge.

Ingold, T. (2010). Footprints through the weather-world: walking, breathing, knowing. Journal of the Royal Anthropological Institute, 16(1), 113-135.

Ingold, T. (2011). Being alive. Essays on movement, knowledge and description. London: Routledge.

Ingold, T. (2015). The life of lines. Oxon: Routledge.

Jarzabkowski, P., Balogun, J., \& Seidl, D. (2007). Strategizing: The challenge of practice perspective. Human Relations, 60(5), 5-27. 
Jarzabkowski, P., \& Spee, P. (2009). Strategy-as-practice: A review and future directions for the field. International Journal of Management Reviews, 11(1), 69-95.

Jarzabkowski, P., Spee, P., \& Smets, M. (2013). Material artifacts: Practices for doing strategy with 'stuff. European Management Journal, 31(1), 41-54.

Jarzabkowski, P., \& Kaplan, S. (2014). Strategy tools-in-use: A framework for understanding "technologies of rationality" in practice. Strategic Management Journal, 36(4), 537-558.

Jarzabkowski, P., Kaplan, S., Seidl, D., \& Whittington, R. (2016). On the risk of studying practices in isolation: Linking what, who and how in strategy research. Strategic Organization, 14(3), 249-259.

Johnson, G., Langley, A., Melin, L., \& Whittington, R. (2007). Strategy as practice. Research directions and resources. Cambridge: Cambridge University Press.

Kaplan, S., \& Orlikowski, W. J. (2013). Temporal work in strategy making. Organization Science, 24(4), 965-995.

Kornberger, M. (2013). Disciplining the future: On studying the politics of strategy. Scandinavian Journal of Management, 29, 104-107.

Kvale, S. (1992). Ten standard responses to qualitative research. Aarhus: Institute of Psychology, Aarhus University.

Mantere, S. (2008). Role expectation and middle manager strategic agency. Journal of Management Studies, 45(2), 294-316.

McNamee, S., \& Hosking, D. (2012). Research and social change - A relational constructionist approach. New York: Routledge.

Mead, G. H. (1932). The philosophy of the present. Amherst, USA: Prometheus Books.

Mead, G. H. (1974). Mind, self and society from the standpoint of a social behaviourist. Chicago, IL: Chicago University Press.

Mintzberg, H., \& Waters, J. A. (1985). Of strategies, deliberate and emergent. Strategic Management Journal, 6, 257-272.

Nicolini, D., Gherardi, S., \& Yanow, G. (2003). Knowing in organizations: A practice-based approach. Armont, NY, USA:

M. E. Sharpe.

Orlikowski, W. J. (2010). Practice in research: phenomenon, perspective and philosophy. In D. Golsorkhi L. Rouleau, D. Seidl \& E. Vaara (Eds.), Cambridge handbook of strategy as practice (pp. 23-33). Cambridge: Cambridge University Press.

O'Shannassy, T. (2015). Strategic management research in the Journal of Management \& Organization: International in orientation with an Australian edge. Journal of Management \& Organization, 21(5), 551-557.

O'Shannassy, T. (2016). Strategic intent: The literature, the construct and its role in predicting organization performance. Journal of Management \& Organization, 22(5), 583-598.

Pedler, M., Burgoyne, J., \& Brook, C. (2006). What has action learning to become? Action Learning; Reseach \& Practice, 2(1), 49-68.

Pettigrew, A. M. (1992). The character and significance of strategy process research. Strategic Management Journal, 13, 697-713.

Regnér, P. (2008). Strategy-as-practice and dynamic capabilities: Steps towards a dynamic view of strategy. Human Relations, 61(4), 565-588.

Revans, R. W. (1977). Action learning and the nature of knowledge. Education \& Training, 19(10), 318-320.

Revans, R. W. (1981). The nature of action learning. Omega, 9(1), 9-24.

Revans, R. W. (1983). Action learning. Its terms and character. Management Decision, 21(1), 9-24.

Revans, R. W. (1992). What is action learning? Journal of Management Development, 1(3), 64-75.

Ripamonti, S., Galuppo, L., Gorli, M., Scaratti, G., \& Cunliffe, A. L. (2015). Pushing action research towards reflexive practice. Journal of Management Inquiry, 25(1), 1-14.

Robson, C. (2011). Real world research. Chichester, UK: John Wiley \& Sons Ltd.

Rouleau, L., \& Balogun, J. (2011). Middle managers, strategic sensemaking, and discursive competence. Journal of Management Studies, 48(5), 953-983.

Ruwhiu, D., \& Cone, M. (2013). Pragmatic leadership: A return to wisdom. Journal of Management and Organization, 19(1), 25-43.

Schatzki, T. R. (2001). Practice theory. In T. R. Schatzki, K. Knorr Certina, \& E. von Savigny (Eds.), The practice turn in contemporary theory (pp. 1-14). London: Routledge.

Schütz, A. (1972). The phenomenology of the social world. Evanston, USA: Northwestern University Press. 
Shotter, J. (2016). Undisciplining social science: Wittgenstein and the art of creating situated practices of social inquiry. Journal for the Theory of Social Behaviour, 46(1), 60-83.

Shotter, J., \& Cunliffe, A. (2003). Managers as practical authors: Everyday conversations for action. In D. Holman, \& R. Thorpe (Eds.), Management and language: The manager as practical author (pp. 15-37). London: Sage.

Simon, H. A. (1991). Bounded rationality and organizational learning. Organization Science, 2(1), 125-134.

Suddaby, R., Seidl, D., \& Le, J. K. (2013). Strategy-as-practice meets neo-institutional theory. Strategic Organization, 11(3), 329-344.

Vaara, E., \& Whittington, R. (2012). Strategy-as-practice: Taking social practices seriously. The Academy of Management Annals, 6(1), 285-336.

Vološinov, V. (1973). Marxism and the philosophy of language. Harvard: Harvard University Press.

Weick, K. (1988). Enacted sensemaking in crisis situations. Journal of Management Studies, 25(4), 305-317.

Weick, K. (1995). Sensemaking in organization. New York, NY: Sage.

Whittington, R. (2006). Completing the practice turn in strategy research. Organization Studies, 27, 613-634.

Whittington, R. (2007). Strategy practice and strategy process. Family differences and the sociological eye. Organization Studies, 28, 1575-1586.

Willert, S., \& Larsen, M. V. (2015). Leaders' use of maps, guiding images and momentary meaningful actions. In M. V. Larsen, \& J. G. Rasmussen (Eds.), Relational Perspectives on Leadership (pp. 129-152). London: Palgrave Macmillan. 